\title{
How Learners' Voices Impacted on the Quality of Teaching and Learning at a Johannesburg Inclusive School
}

\author{
Gladys Ayaya \\ St Stithians College, South Africa
}

\begin{abstract}
In comparison to western countries, the inclusion of children with barriers to learning in regular classrooms that requires inclusive teaching and learning is relatively new in South Africa and is not yet on offer in all schools except for a very small percentage of schools that are now inclusive schools. Most learners that experience barriers to learning continue to be disadvantaged because of the way teaching and learning happens. This paper aims to outline the effect of learners'voices on enhancing teaching and learning in South Africa's inclusive schools. The importance of inclusive teaching and learning as a starting resource for planning and implementation of measures of developing intellectual abilities of a child was explored. Using Participatory Action Research (PAR) that required observations, interviewing and focus group meetings, 20 learners at an inclusive school in Johannesburg were engaged in a research project over a six-month period. Results from an inductive analysis of qualitative data revealed that at the start of the research, many of the learners felt unwelcome in the classroom and that their learning needs were not being met because the teachers did not fully understand how to teach in an inclusive classroom environment, and that their teaching practices were not necessarily supporting inclusive education. Upon completion of the PAR process, the learners acknowledged that their teachers had become more accepting of their barriers to learning, and that they were teaching in more creative and collaborative ways, and that they applied effective inclusive teaching methods which made them feel accepted. Teachers also expressed problems in their practice and welcomed learners' suggested measures.
\end{abstract}

\section{Introduction}

South Africa's journey to inclusive education began in 2001 with the release of the Education White Paper No. 6 policy on special needs education which states that "Inclusive education is about acknowledging that all children and youth can learn and that all children and youth need support as is the case of learners with barriers to learning who need support in order to achieve; and that inclusive education is also about accepting and respecting the fact that all learners are different in some way and have different learning needs which are equally valued and an ordinary part of our human experience." [8]. The policy stipulates that, children with barriers to learning should be accommodated in inclusive schools, also known as full-service schools, where they are taught together with ordinary learners without discrimination of their learning needs. The emergence of full-service schools meant that they would admit all learners regardless of their barriers to learning.

The implementation of inclusive education in South Africa was, therefore, the beginning of having learners with diverse learner needs in one classroom, in a new type of schools called full-service schools (or inclusive schools). As a result, teachers of full-service schools had to adapt their teaching to accommodate the various diverse needs and barriers to learning in their classrooms. Teachers of full-service schools needed to be trained and equipped with the skills and knowledge that support multi-level, effective classroom instruction and inclusive teaching strategies so that the learners' diverse needs are catered for.

Research by Walton [18], on the voices of learners with barriers to learning that was done towards seeking better approaches to inclusive education, recommends that interventions to issues such as social exclusion and negative attitudes can be reached if the learner's views are expressed and used as a source of knowledge for inclusion. It was by considering this that this paper set to find out, using Participatory Action Research (PAR), how learners' voices can be used to enhance inclusive teaching and learning practices in diverse classes. Existing research shows the importance of incorporating learners' voices in research instead of making decisions based on parent and teacher ratings only [3; 13]. Parent and teacher ratings leads to learners being misunderstood and left suffering under the circumstances. As much as teachers may have good intentions of teaching learners as best as they know, learners also have their expectations [3]. Research by Leseyane and others [13] contend that learners who were interviewed about their experiences in full-service schools narrated that they were bullied, made to feel embarrassed by teachers in class when they got answers wrong, and that they felt misunderstood with impatient teachers who ridiculed their progress. 
Teachers are expected to be researchers [11], and as part of good practice, teachers are trained to use the data collected from their teaching to improve their practice. They test the evidence, reflect and analyse individual students as part of best practice.and most teachers preferred to send these learners to remedial classes where they were given differentiated work and taught by remedial teachers. This lack of sufficient training for teachers has led to their misunderstanding of learner needs, causing teachers to have negative attitudes towards learners with barriers to learning in diverse classrooms [11]. On the contrary, some researchers [13] advocate for the need for learners' voices in research so that teachers have a deeper understanding of how best to teach them, hence the need for this research.

The rest of the paper is organised as follows: Section 2 looks at the research problem, questions and guiding theory. Section 3 deals with methodological issues as captured under 3.1. Findings are presented in section 4 to allow for a discussion of the results in section 5. Based on the discussion of results, conclusions are drawn as shown in section 6.

\section{Problem statement and research question}

\subsection{Problem statement}

In this research, we seek to find the impact that learners' voices have improving the quality of teaching and learning in South Africa's inclusive schools.

\subsection{Research objectives}

In line with the problem statement above, the objectives of the study were derived.

- To acknowledge learners' understanding of inclusive education.

- To identify the existing inclusive teaching practices that learners found beneficial.

- To use the identified best inclusive teaching practices to improve the quality of teaching and learning.

\subsection{Guiding theory}

This paper is guided by the expectations set in the South African government policy of White Paper no. 6 on Inclusive education [8] which gives broad guidelines on how learners with barriers to learning are to be accommodated, and these include: "accepting and respecting the fact that all learners are different in some way; having enabling education structures, systems and learning methodologies to meet the needs of all learners; maximising the participation of all learners in the culture and the curricula of educational institutions and uncovering and minimising barriers to learning". The policy on Screening, Identification, Assessment and Support [7] lays out further guidelines and details of how to implement inclusion. In addition, there are volumes of research on internationally recognised practices in inclusive teaching that are reported to have had some success and could be tapped into. Resources on differentiated teaching have been used for training teachers of inclusive schools, for example, the use of the layered curriculum $[6 ; 16]$. This paper therefore applies the knowledge of inclusive teaching to support learners' voices in coming up with workable solutions for the inclusive South African classroom teaching and learning.

\section{Research methods}

This research was a part of a bigger $\mathrm{PhD}$ research that sought to develop a teaching framework for teaching diverse classes in Johannesburg East District. In attempting to address the research problem and the research objectives, the researcher was aware of her own beliefs, philosophical assumptions and methodological values. These assumptions may impact on how the research was carried out and are disclosed to understand the intellectual setting in which the research was conducted. The theory of knowledge (epistemology) of the researcher describes how one can discover underlying principles about social phenomena and how one can demonstrate knowledge [19]. The researcher's personal experience with an inclusive education ignited her interest in the topic. To mitigate her biases, a structured datagathering method was used to capture the voices of learners over a period of 6 months.

An ontological position comprises the researcher's view on the very nature and essence of the research reality, being set in the South African context. The researcher is a constructivist who believes that knowledge is constructed from facts associated with real-life cases and their context. If the researcher found repeated mentions of practices and praxis, she could generalize from them. Her interest was, mainly, to identify voices to guide the future inclusive teaching practices.

\subsection{Research design}

The research was designed under these eleven guiding principles under Participatory Action Research (PAR) design [19].

(i) Research Problem: Teaching inclusive classrooms remains a challenge as diverse learner needs are not met, yet learners' voices have inadequately been factored in the design and implementation of inclusive teaching practices.

(ii) Research purpose: To include learners' voices in the designing of good inclusive teaching practices. 
(iii) Research problem: The effect of learners' voices on enhancing teaching and learning in South Africa's inclusive schools.

(iv) Context: Inclusive teaching and learning in South Africa's inclusive elementary schools.

(v) Proposition: Learners' voices have no relevance in the design and implementation of inclusive teaching practices.

(vi) Hypothesis: Teachers and parents know the needs of learners with barriers to learning.

(vii) Phenomenon investigated: Learners' voices in inclusive teaching practice.

(viii) Unit of Observation: Learners and teachers

(ix) Method: Participatory Action Research.

(x) Logic linking the data to the proposition: Inclusive teaching practices deemed effective in learning by the learners were investigated using learners' voices to determine if indeed they were effective. Documentation of learners' voices on how to improve teaching and learning for learners with barriers to learning was done.

(xi) Criteria for investigating the findings: Factors and methods that learners use to verify acceptance and belonging in inclusive environment, processes that teachers use to accommodate learners' voices verified, practical application of verified voices.

\subsection{Research site}

A primary school that had been in operation for over close to century and had converted to full-service in the past five years in Johannesburg East District was chosen as a research site. Johannesburg East district has 83 government primary schools, of which only five are full-service schools. The school is situated in a poor socio-economic area, with most of the parents as casual labourers, hence the school relies $100 \%$ on government funding. Prior to becoming a full-service school, the teachers in the selected school had been trained on inclusive teaching methodologies over a period of a year by attending weekly seminars at a local university. However, there had been no follow-up training after the inception of inclusive education, yet some of the trained teachers had since left the school, while new staff, unfamiliar with inclusion had joined the school.

\subsection{Selection of participants}

Twenty learner participants with diverse learning needs were selected using the purposive sampling technique. The 20 learners selected were from the middle phases of grades 5, 6 and 7, which are also the most senior grades in primary school. Purposive sampling is a technique that enabled the researchers to select learner participants based on predetermined criteria, for example, learners from the four broad categories of "barriers to learning" namely, Systemic barriers; Societal barriers; pedagogic; and intrinsic barriers to learning.

\subsection{Ethical consideration}

Research protocol procedures were followed, with research ethics clearances being obtained from relevant authorities beforehand. All the research participants had to express interest, followed by a signed consent from their parent/guardian. They participated on a voluntary basis and were kept anonymous, although their Learning Support Educator (LSE) that they had worked with for many years and acted more like their advocate because of her keen interest in the learners was always present during the learner focus group discussions to make them feel comfortable and to help translate the questions for the children that needed assistance.

\subsection{Data collection process}

As this was part of a larger research on developing a teaching framework for diverse classes, PAR, which follows a spiral of characteristic self-reflective cycles was applied. The first phase involved planning for the research, which was followed by the intervention/action phase, following the pertinent observations that had been made in various forms. The new interventional strategies were then implemented, and the cyclic process repeated, continuing until enough understanding of the problem and solution to the problem had been achieved [2]. Qualitative data was collected from observations of learners, focus group discussions with learners as well as with teachers. The researcher (first author) held a briefing session with the learners to help them understand how the focus group sessions worked.

Planning is the initial phase of PAR. During preplanning, background information on the school was collected through interviews with the school head, deputy heads and some of the heads of departments. The planning phase was when the PAR research objectives were identified. It involved the researcher and research team identifying a problem, acknowledging it, and assessing the needs of the community [1]. It was therefore a collaborative effort that involved a series of focus group meetings and brainstorming to define the aim of the research clearly.

The observation phase looked at the current practice by determining what practices the teachers used as reported by the learners. This helped determine how learners with diverse needs were being taught. Observations were made by the author to lead her into deeper understanding of the context and provide knowledge of the context in which events occurred.

The action phase involved putting the newly identified solutions and desired outcomes into practice. The researcher cleverly used the problems identified by the learners to challenge the teachers in their focus group meetings, without exposing any learners, to self-critique their current practice and 
come up with workable solutions. Regular interviews with learners and their teachers were conducted to ascertain their progress and offer support and reenforcement on implementing PAR where needed. In this phase, teacher participants implemented the agreed upon teaching strategies that learners preferred by applying the knowledge from the learner participants' group discussions.

The reflection phase involved the learner participants reflecting on how their teachers had changed, what had worked, and what needed improvement. Evaluating the outcome yielded realisation of how well the research process had gone, but it also helped the research team critique the process to improve it. A review of all the observation and action phases was discussed, and learners agreed on the positive changes that had taken place. The cycle with the teacher participants was repeated until all the suggested comments from the learners were implemented and the practice reached a theoretical saturation.

\subsection{Data analysis}

Verbatim information from the learners was transcribed by the key researcher. Information given in a native language was first translated by the LSE teacher before transcribing. The written information was read to the learners to ensure accuracy and agreed upon. The data was then coded and grouped into themes, after which the researcher used the information for triangulation when meeting with the teacher researchers to reach a consensus on way forward. Analysis took place in the following stages: reading of data, identification of data codes and categories and deriving themes from data.

\section{Findings}

The findings were arrived at using both group interpretative analysis and the main researcher's meta-analysis of all the data collected at the various stages of PAR. The findings were organised in accordance with the objectives set in each of the PAR phases. The themes of the findings were attributed to the South African government policies of White Paper no. 6 on Inclusive education [8] and the policy on Screening, Identification, Assessment and Support [7] in addition to internationally recognised practices in inclusive teaching that include differentiated teaching using the layered curriculum [16]. The following themes were identified through data analysis.

\subsection{Learners' understanding of inclusive education}

4.1.1. Learners' voices challenged the practice of inclusive schooling. The practice of copying inclusive practice from elsewhere and implementing it without knowing the learners concerned was about to change. Learners were able to express their understanding of what a full-service school meant to them, giving inclusive schooling a deeper meaning as expressed by the very learners with barriers to learning. One learner put it this way:

"It is a school where they accept all the children no matter how good or bad you are"

The learners here touched on unconditional acceptance of all learners, regardless of their capabilities [8]. This unconditional acceptance was to include supporting them with their academic challenges, as this learner added:

"They help you when you are struggling with reading, writing and many other things."

The study seems to point out that learners' voices gave a deeper perspective into the meaning of inclusive schooling as the learners with diverse needs were given an opportunity to explain their understanding of inclusive schooling. This gives meaning that is based on expectation and needs of the learners, which is important for inclusive teaching.

However, this meaning of inclusive schooling posed a challenge to the teachers who felt that unconditional acceptance of all learners regardless of their learning needs, and support was not a reality given the large class sizes that they faced. Class sizes of 50 to 65 learners, with limited support that the teachers received did not allow this meaning of inclusive schooling to be realised as one teacher put it:

"There are problems when it comes to supporting the learners with barriers to learning. There is a gap, and we no longer get professional support that we used to get. We do not get support on how to identify them. We as teachers have become the teacher, support, social worker, because government support is not readily available. The teacher assistants that used to come in to help us no longer come."

The challenge of overcrowding in classes was witnessed by the researcher as a major deterrent to support of learners with barriers to learning, especially for those teachers who did not have the necessary skills to teach in an inclusive environment.

4.1.2. Teachers were made to understand inclusion at a deeper and personal perspective by listening to learners' daily struggles and experiences. The learners interviewed were able to explain their specific barriers to learning in the way they understood best. Examples include:

"I struggle with reading"; or "I struggle to see clearly on the board"; or "I struggle to follow when the teacher is talking fast"; or "I don't understand Maths".

Learner responses ranged from broad subject generalisations to specific barriers and skills that they struggled with. This included auditory processing difficulties as witnessed with a learners' who 
complained of not being able to follow when the teacher is talking. There were visual perceptual and motor coordination related difficulties reported, as seen in the example of the learner who complained that he could not see clearly on the board. The wide range of barriers to learning and challenges experienced by the learners helped define the expectation of inclusive teaching from the learners' perspective. This signified the importance of teachers' understanding of how to carry out teaching at an inclusive school, based on the diverse needs of the learners.

Learners' voices therefore enabled the research team to understand inclusive teaching more clearly based on the diverse needs of the learners in the context of a full-service school. The needs had a lot to do with how the subject matter was taught, as well as neurological challenges based on sight, hearing and attention.

\subsection{Identifying existing inclusive teaching practices that learners found beneficial}

4.2.1. Learners' voices expounded on teachers' understanding of learner needs, leading to collaborative working among the teachers and parents. Here, learners were able to give various examples of instances where some of their teachers had helped them work around their barriers. Most of their examples illustrated the need for a good, balanced teaching approach that puts the learner first in lesson presentation, as opposed to putting the curriculum first. The idea of giving learners enough illustrations and examples for them to understand a concept was echoed by many learners. They explained that when a teacher gives them examples and illustrations, it helps them understand better. This also included giving them work to try out as examples as one learner explained:

"My teacher gives me problems in Maths, and she checks if I am doing right".

Some learners explained that they preferred to go for extra support with the learning support teacher (LSE) who they felt explained better.

"I go for extra classes (with the learning support teacher), and they explain better".

This pointed to the feeling of being understood by the learners from the way a teacher explained concepts. LSE teachers having been trained in remedial teaching were more likely to simplify the explanations and make it easier to understand.

Through the sharing of such sentiments, teachers were able to learn from each other preferred ways of teaching diverse classes, hence there was evidence from the study that learners' voices helped the teachers at a full-service school context to build communities of practice that cooperatively work together in ways that significantly improved teaching. This communication encouraged the sharing of information between colleagues and hence provided a platform for interaction and better inclusive practice.

Further to this, teachers were also able to cooperate with parents to gather more information on the learners as they understood the importance of knowing the learning needs of their learners. This spill over to teachers who started to contact parents to get an insight into their children's difficulties contributed to good teaching practice. The use of learners' voices also enabled the research team to uncover how family and social circumstances of learners affect inclusive teaching. However, it was not always easy to get information from the parents as the study also revealed lack of parental involvement in the education of their children. For example, the parents were unable to help with homework, or to discuss the children's psychological or medical needs with the teachers owing to illiteracy levels and overdependence on the government, and this had a direct impact on the inclusive teaching.

4.2.2. Learners' voices brought about transformation in teachers' attitudes and ways of thinking. Initially, there were concerns by learners of being punished for not doing work which they did not understand:

"I don't like it when my teacher punishes me for not doing my homework even when I don't understand."

Or when the teachers shouted at them because they did not understand them.

"I don't like it when the teacher shouts at me and calls me names"

This may have demonstrated the frustration of teachers, in their efforts to teach, yet not understanding why some learners were not getting it. Most of them agreed that their form of discipline needed to move away from the punitive methods. And vice versa, they also wanted to see fellow learners respecting their teachers better and not making noises in class. They wished that the learners could stop engaging in bullying and stop fighting. Discussions with the teachers led to a shift over time.

As the PAR process progressed, learners seemed to have been encouraged by their teachers to go to them for one-on-one assistance at the end of the lesson. Many learners explained that they go to the teacher when they do not understand.

"In EMS, I go to the teacher and ask if I don't understand".

This indicates a more welcome atmosphere where the learners felt free and comfortable to approach the teacher. However, relying on the learners approaching the teacher for support may work for the more confident learners, and not for the ones who may feel intimidated in any way. Learners also stated in their responses that they preferred teachers who used humour when teaching. They mentioned that it made the lessons more exciting. 
As the PAR process continued, learners reported that punishment for those who did not understand their homework had significantly reduced since the initial meeting. Some teachers had completely stopped punishing them, but a few were still punishing them for not knowing their work. Shouting had also reduced as the teachers were starting to know their learners better and the learners were starting to feel welcome in the classrooms.

There was a consensus from the learners that the teachers had become more helpful over the past few months. For example, one learner reported.

"They tell (encourage) us to ask questions if we don't understand."

Most of them said that they were getting more assistance with homework. They had become more approachable and were giving them information that they asked for more readily, as well as teaching using more examples. Initially, the learners had mentioned that they were often punished for wrong behaviour instead of being taught good behaviour, but this started to change.

4.2.3. Learners' voices opened doors for choice and flexibility in their learning. The ability of learners to express their concerns to their teachers enabled the teachers to make adjustments to the curriculum delivery. For example, one learner expressed.

"I struggle to copy down work and my handwriting is not good"

Such an awareness enabled teachers make simple adjustments like giving students photocopied notes. Teachers were able to debate at focus group session how best to work with such a learner and came up with workable alternatives. The location that the learners sat in the classroom also mattered to the learners with visual difficulties, short sightedness, and concentration difficulties, as one learner put it.

"I understand if I sit closer to the front, and I can concentrate."

Other learners preferred a change in venue. They mentioned that they liked it when they went to the computer laboratory. However, due to crime in the area, computers were often unavailable due to robbery. The teachers therefore had to supplement the use of internet by sourcing extra work for the learners as one learner stated.

"My Sotho teacher gives me extra words to learn so that I can understand".

Towards the end of the PAR process, the learners reported that there was more flexibility in the environment they learnt from as to compared to before PAR. For example, the teachers were alternating venues such that they could go and learn from a different class or go outside for creative arts. Although the changes were not $100 \%$ thorough, the learners seemed happy with the progress.
4.2.4. Learners' voices challenged teachers to become creative and innovative in their teaching. Learners explained that they wanted the teachers to teach them in ways that they understood [16]. More often, they felt that they did not understand the lessons and that the teachers did not give them enough practice before moving to the next topic. One learner mentioned that she preferred to be given more homework for practice.

"I want the teacher to give me more practice words in English and to explain better. They should give us more books and more examples".

Learners also expressed their desire to be afforded the opportunity to work on computers which could help them with spelling. There was a unanimous interest in having more lessons of Life skills and Physical Education as the learners mentioned that they enjoyed these classes because they involved physical creativity. There was a report of teachers helping learners more as well as doing more practical skills that involved handwork.

The learners also mentioned the problem of stealing among some learners, an issue that had led to the school banning them from bringing cell phones to school due to the increased discipline issues around cell phone theft. This problem had therefore made it difficult for them to refer to phone technology in the absence of computers.

The teachers therefore tried to take their classes to the library or outdoors for a reading lesson to stimulate learning in new environments. They also placed more pictures and charts in the classroom to make it warm and welcoming for the learners. However, one hindrance to creativity was a lack of resources and support. The barriers that presented a challenge to inclusive teaching included broken computers, theft, a limited number of books and charts and lack of smart technology.

\subsection{Using the identified good inclusive teaching practices to influence change}

4.3.1. Learners' voices created more collaborative teachers who valued group work among the learners. It was reported that the teachers were organising the learners to work in groups, which they enjoyed as one learner put it.

"The group members help us; they know what to do and we help each other"

Learners expressed that they learnt more when their group members explained step by step in simple ways that they understand.

Through PAR, teacher participants had been paired up to observe each other, leading to collaboration and teamwork. They learnt from each other better ways of grouping learners so that the learners could learn from each other. The participants shared information within departments while supporting and learning from each other. 
"In our groups, I can ask the others to explain to me, and I am not afraid to ask. My work in the group is to keep time so that everyone can speak for one minute only and everyone has a chance to speak".

The teachers also learnt collaboration through handing over of information from one grade to the next at the end of the academic year, so that the next teacher got the learners' records and learner profiles and could assist them better. It can therefore be said that learner's voices made teachers to collaborate as colleagues and this collaboration enhanced teachers' well-being.

The study has indicated that learners' voices necessitated teacher change strategy towards inclusive teaching in full-service schools, as one teacher mentioned:

"I am now sharing the information we learn here in our department meetings and the other teachers are enjoying getting new ideas and information. This will continue in all our meetings so that we all help each other."

4.3.2. Learners' voices impacted teachers to become more reflective of their practice. The learners became confident when answering question towards the end of PAR. They said that they wanted their ideal inclusive class to have:

"...having more life skills and physical education lessons including more sports".

“...having more natural science practical and demonstration lessons because we enjoy practical lessons".

"...to include more human health lessons".

The desire for them to be taught English in a way that would enable them to express themselves and do well was also expressed by a learner who said.

"I want them to teach English well so that we understand how to speak it. Some teachers explain in Sotho, and I don't understand Sotho, but if they explain in Zulu I understand."

The teaching approaches by the teachers had also changed. They were now doing more project-based learning. They were also using more visuals for illustrations. There was also evidence that they had changed the ways in which they assessed. Learners were now able to demonstrate what they had learnt in different forms. An example is when a learner stated:

"They ask us to draw, and I like it, because I don't like writing."

During the reflection phase, the PAR process allowed the teacher participants to reflect on their work in terms of what was working and what was not, and if not, how they could make it work better. One teacher participant reflected on the process:

"I observed based on what we spoke about. During the shared reading lesson, I realised that in my teaching, I had not been challenging my learners to express themselves. Most of them were only comfortable with yes/no answers or one-word answers.... This week, I asked them questions that required them to think and explain, and they found it hard to answer, most of them preferring to keep quiet, so it is something that I would like to try and build on them. They struggle to express themselves ... but they are getting better with time".

The study has shown learners' voices to be a viable influence in shaping the way teaching happens in inclusive classes. There was also a lot of noticeable change and professional growth in the teachers, for example, on reflecting, they were able to articulate the practices that they wanted to change.

\section{Discussion of Findings}

The understanding of an inclusive school as a school which accepts all children regardless of their barriers to learning is endorsed $[4 ; 14 ; 17]$ as key to the success of good inclusive teaching practice. The need for the support of all learners with diverse needs is well-documented by the South African government in Education White Paper no. 6 [8] which emphasises that inclusive education systems should also be "Enabling education structures, systems and learning methodologies to meet the needs of all learners." From the study, learners were able to express their understanding of what a full-service school meant to them, including the need for support in the areas that they struggled with. This helped define inclusive teaching from the perspective of the learners, giving it more meaning and relevance.

Inclusive schooling should incorporate a pedagogical approach that responds to learner needs instead of promoting the marginalisation of some learners that already exists in the classroom. This can be done by offering unconditional recognition and acceptance of all learners [12], and by making learners' voices heard. The challenges experienced while dealing with diverse classes are supposed to be viewed as a teacher's professional dilemma that stretches the teachers to think creatively while applying their knowledge and seeking consultations in order to come up with workable solutions to those challenges. It is important for teachers to understand that the challenges and barriers to learning that are experienced by their learners are indications for them to make the correct adjustments to their teaching, and plan accordingly $[6 ; 16]$. Such adjustments can include curriculum adaptation and differentiation.

The South African government is intentional in its expectation on the importance of teachers understanding the different barriers to learning that are experienced in an inclusive classroom. These are grouped into four broad categories of, systemic barriers, societal barriers, pedagogic barriers, and intrinsic barriers $[7 ; 8]$. Without proper understanding by the teachers on how all these issues affect the learners in their classroom, access to teaching and learning becomes limited. Learners' voices therefore informed teachers of their different learning needs, hence, helping to define inclusive teaching more 
clearly based on the specific yet diverse needs of the learners in their specific context of an inclusive schooling [6]. Florian and Spratt [12] emphasise the importance of teachers demonstrating their understanding of how learning happens, understanding social justice, and becoming active professionals by putting knowledge into action. Learners were able to give various examples of instances where some of their teachers had helped them work around their barriers. These examples helped teachers to learn from the shared experiences of what worked best for the learners. With time, this created room for flexible teaching schedules that allowed teachers to plan collaboratively and manage their workload.

Collaboration led to a more balanced teaching approach, instead of teachers sticking to familiar practices. In line with this, research shows that more teachers value the opportunities to share instructional strategies with their colleagues [9]. Some learners expressed that they preferred to go for extra support with the LSE who they felt explained better, hence prompting some teachers to work closer with the LSEs, which led to their better understanding of how best to assist these learners. LSE teachers have been trained in remedial teaching and are more likely to understand inclusive teaching practices and hence have skills and knowledge that they can share with teachers if afforded the chance to collaborate. They were also more informed because they had better and longer relationships with parents on how best to assist these learners. Collaboration was therefore appreciated in the form of sharing knowledge and expertise, which gradually grew and became more harmonised.

The exclusion of learners with barriers to learning from their right to education is a well-documented fact that is attributed to traditional perceptions and misunderstood views that assume learning disabilities are either a diseases or social deviance $[4 ; 5]$. This study confirmed that such views still exist considering some of the statements made by the learners on how they were treated for not understanding their homework. The learner participants indicated that they felt that they were disadvantaged because their educational needs were not being adequately met as they did not grasp the subject matter in the way it was taught to them. Some of the teachers who did not have training in inclusive schooling treated learners with barriers to learning from a deficit perspective $[11 ; 20]$, which created wrong beliefs and stereotypes that creeped through the pedagogy due to a lack of general awareness of their difference. Learners' voices helped bring reason into the teachers' understanding of their needs, creating a paradigm shift. The learners reported that more and more teachers were beginning to teach in ways that they understood compared to before the onset of the research.

A lack of sufficient training for inclusive teaching causes many teachers to practise inflexible teaching methods that do not favour diverse classes [10]. The PAR process challenged them into a considerable shift towards embracing new ideas in teaching. The teachers became more flexible at accommodating learner needs. This led to a better understanding of how to teach diverse classes using innovative methods that they formulated on their own. It required them to come up with initiatives unique to each scenario, be creative and reflect on what was working and what needed change. Literature indicates that voices of learners are very instrumental in enhancing inclusion [18]. They make teachers to become flexible in choosing how to teach them. While comparing the responses of learners at the beginning of this study on how they perceived how they were taught, and how they felt at the end of the study, there was a significant positive change.

Learners expressed the desire to be taught in ways that they understood. Howard Gardner advocated for teachers to incorporate the learning preferences and strengths of their learners in their everyday lessons, prompting creativity and innovation in lesson design. Learners preferred the opportunity to incorporate technology in their learning so that they could get help with spelling. The use of technology has proved more important and one that we cannot do without as a tool for effective inclusive teaching and learning. In addition, it is endorsed by the SIAS policy [7] when the government allows learners accommodation for examinations that include, the use of a computers to type answers (for learners with severe handwriting difficulties), the use of electronic readers (for learners with severe dyslexia) and braille (for learners with severe visual impairment) to name but a few. This has become universally accepted as a non-negotiable with the introduction of online learning due to COVID-19 pandemic.

Learners voiced a strong interest for practical activities in their learning, as opposed to traditional instructional methods that tended to emphasise whole group lecture methods [10]. The teachers therefore tried to take their classes to the library or outdoors for a reading lesson to stimulate learning in new environments. They also placed more pictures and charts in the classroom for the learners to create a warm and welcome feeling. Therefore, it is important for teachers to demonstrate inclusive teaching by varying their teaching methods and strategies and using creativity to meet the needs of the learners as opposed to the current practice that is lecture style and not inclusive [15].

It was reported that the learners enjoyed groupwork because they could get assistance from their friends, as well as work together, and this, they enjoyed. The use of groupwork in teaching is a good inclusive practice that transforms teaching into best practices and promotes belongingness [1]. Learners expressed that they learnt more when their group members explained step by step in simple ways that they understood. Through collaboration and 
teamwork, teachers learnt from each other better ways of grouping learners so that the learners could assist each other as recommended by Vygotsky's principal of zone of proximal development. Groupwork also created a sense of belonging in all learners by eliminating labelling and bullying hence demystifying stereotypes that were previously associated with barriers to learning. The teachers shared information on groupwork within their departments and strengthened the departments to work even better.

The study found that initially many teachers were not open to listening to the voices of their learners and preferred to continue with their traditional instructional methods that tended to emphasise whole group lecture methods, a practice that has been welldocumented in research [10]. However, with time, there was a considerable shift towards embracing new ideas suggested by the learners' voices. Learners' voices enabled the teachers to reflect on their own teaching hence have a better understanding of how to teach diverse classes in more creative ways. Because of learners' voices, the teaching approaches by the teachers changed significantly. They were now doing more project-based learning. They were also using more visuals for illustrations. There was also evidence that they had changed the ways in which they assessed. Learners were now able to demonstrate what they had learnt in different forms. The study has shown learners' voices to be a viable influence in shaping the way teaching happens in inclusive classes. There was also a lot of noticeable change and professional growth in the teachers, for example, on reflecting, they were more aware of their own teaching and hence able to articulate the practices that they wanted to change.

\section{Conclusion}

This study demonstrated that learners' voices can help shape inclusive school practices. Literature review results indicates that the voices of learners in enhancing inclusion are very instrumental. Rather than being viewed as consumers of knowledge, learners become co-producers of knowledge. Walton [18] recommends intentional incorporation and participation of the voices of learners in the production of knowledge. A comparison between the responses of learners at the beginning of this study on how they perceived how they were taught, and how they felt at the end of the study showed a significant positive change.

The challenges experienced while dealing with diverse classes are supposed to be viewed as a teacher's professional dilemma that stretches the teachers to think creatively while applying their knowledge and seeking consultations in order to come up with workable solutions to those challenges. This study verified that learners' voices are viable influence in shaping the way teaching happens in inclusive classes. The teachers improved their approach to group work, they started collaborating, their teaching methods became more inclusive, their teaching spaces became more welcoming, and their assessments were graded better. Some of the practices that the learners enjoyed included the variation of learning spaces to include outdoors, the use of multiple ways of engagement which included the application of more practical work in their lessons. The learners also enjoyed the fact that their teachers understood their learning challenges, enabling them to teach accordingly, and that they had developed unconditional acceptance for all learners regardless of their barriers to learning. As a result, we had much happier learners.

It is however important to acknowledge that the study took place in only one inclusive school in a lowincome area of Johannesburg and the findings may not be conclusive for other school contexts. The study serves as a base for further research and discussions about the enhancement of inclusive teaching and learning in inclusive schools using learners' voices.

\section{References}

[1] Ainscow, M., Booth, T., \& Dyson, A. 2003. Understanding and developing inclusive practices in schools. ESRC TLRP Phase I Network: University of Manchester.

[2] Ayaya, G., Makoelle, T. M. \& van der Merwe, M. 2020. Participatory Action Research: A Tool for Enhancing Inclusive Teaching Practices Among Teachers in South African Full-Service Schools (SO-19-1630). SAGE Open Publication.

[3] Bansilal, S., James, A., Naidoo, M. 2010. Whose voice matters? LEARNERS. South African Journal of Education, $30(1)$.

[4] Carrington, S. 1999. Inclusion needs a different school culture. International Journal of Inclusive Education (3)3, pp. 257-268.

[5] Croft, A. 2012. Promoting access to education for disabled children in low-income countries: Do we need to know how many disabled children there are? International Journal of Educational Development.

[6] De Jager, T., 2011. Guidelines to assist the implementation of differentiated learning activities in South African secondary schools. International Journal of inclusive Education, 17(1), pp. 80-84.

[7] Department of Basic Education. 2014. Draft policy on screening, identification, assessment and support.] Available at: http://www.education.gov.za/. (Access Date: 17 October, 2020).

[8] Department of Education. 2001. Education White Paper 6: Special needs education, building an inclusive education and training system. Government Printers. Pretoria. www.thutong.doe.gov.za/ResourceDownload. (Access Date: 17 March, 2021). 
[9] Dreyer, L. 2013. Exploring the changing role of learning support teachers in the Western Cape, South Africa. Perspectives in Education, 33(2), pp. 54-64.

[10] Dymond, S., Renzaglia, A., Rosenstein, A., Chun, J., Banks, R., Niswander, V., \& Gilson, C. 2006. Using a participatory action research approach to create a universally designed inclusive high school science course: A case study. Research and Practice for Persons with Severe Disabilities, 31(4), pp. 293-308.

[11] Engelbrecht, P., Nel, M., Smit, S., \& Van Deventer, M. 2016. The idealism of education policies and the realities in schools: The implementation of inclusive education in South Africa. International Journal of Inclusive Education, 20(5): pp. 520-535, DOI: 10.1080/13603116.2015.1095250.

[12] Florian, L. and Spratt, J. (2015). Inclusive pedagogy: From learning to action. Supporting each individual in the context of everybody. Teaching and Teacher Education Vol 49: 89-96.

[13] Leseyane, M., Mandende, P., Makgato, M., \& Cekiso, M. 2018. Dyslexic learners' experiences with their peers and teachers in special and mainstream primary schools in North-West Province. African journal of disability, 7(0), 363. doi:10.4102/ajod.v7i0.363.

[14] Lindsay, G. 2007. Educational psychology and the effectiveness of inclusive education/mainstreaming. British Journal of Educational Psychology 77, pp. 1-24.

[15] Loreman, T. 2010. Essential inclusive educationrelated outcomes for Alberta pre-service teachers. The Alberta Journal of Educational Research, 56(2).

[16] Nunley, K.F. 2006. Differentiating the high school classroom: Solution strategies for 18 common obstacles. Corwin Press, California.

[17] Rodesiler, C., McGuire, J. 2015. Ideas in practice: Professional development to promote universal design for instruction. Journal of Developmental Education, 38(2): pp.24-30.

[18] Walton, E. 2011. They discluded me: Possibilities and limitations of children's participation in inclusion research in South Africa. Perspectives in Education, 29(1).

[19] Yin, R.K. 2003. Case study research: Design and methods (Applied social research methods), $3^{\text {rd }}$ edn., Applied social research methods Series Volume 5, London: Sage Publications.

[20] Zion, S., \& Sobel, D. 2014. Mapping the gaps: Redesigning a teacher education program to prepare teachers for inclusive, urban schools. Journal of the International Association of Special Education, 15(2), p 6373. 
Literacy Information and Computer Education Journal (LICEJ), Volume 12, Issue 2, 2021 